Conf $94 / 203-29$

\title{
A Comparison of Photovoltaic Module Performance Evaluation Methodologies for Energy Ratings
}

\author{
RECEIVED \\ OCT 201995 \\ OSTI
}

B. Kroposki, K. Emery, D. Myers,

L. Mrig

Presented at the

First World Conference on Photovoltaic

Energy Conversion

December 5-9, 1994

Waikoloa, Hawaii

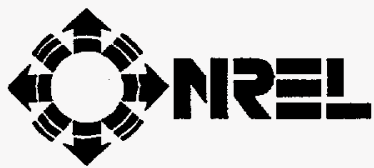

National Renewable Energy Laboratory 1617 Cole Boulevard

Golden, Colorado 80401-3393

A national laboratory of the U.S. Department of Energy Managed by Midwest Research Institute for the U.S. Department of Energy under contract No. DE-AC36-83CH10093

Prepared under Task No. PV560103

October 1995 


\section{NOTICE}

This report was prepared as an account of work sponsored by an agency of the United States government. Neither the United States govemment nor any agency thereof, nor any of their employees, makes any warranty, express or implied, or assumes any legal liability or responsibility for the accuracy, completeness, or usefulness of any information, apparatus, product, or process disclosed, or represents that its use would not infringe privately owned rights. Reference herein to any specific commercial product, process, or service by trade name, trademark, manufacturer, or otherwise does not necessarily constitute or imply its endorsement, recommendation, or favoring by the United States govemment or any agency thereof. The views and opinions of authors expressed herein do not necessarily state or reflect those of the United States government or any agency thereof.

Available to DOE and DOE contractors from:

Office of Scientific and Technical Information (OSTI)

P.O. Box 62

Oak Ridge, TN 37831

Prices available by calling (615) $576-8401$

Available to the public from:

National Technical Information Service (NTIS)

U.S. Department of Commerce

5285 Port Royal Road

Springfield, VA 22161

(703) $487-4650$ 


\section{DISCLAIMER}

Portions of this document may be illegible in electronic image products. Images are produced from the best available original document. 


\title{
A COMPARISON OF PHOTOVOLTAIC MODULE PERFORMANCE EVALUATION METHODOLOGIES FOR ENERGY RATINGS
}

\author{
Benjamin Kroposki, Keith Emery, Daryl Myers, and Laxmi Mrig \\ National Renewable Energy Laboratory \\ 1617 Cole Blvd., Golden, CO 80401, USA
}

\begin{abstract}
The rating of photovoltaic (PV) modules has always been a controversial topic in the PV community. Currently, there is no industry standard methodology to evaluate PV modules for energy production. This issue must be discussed and resolved for the benefit of system planners, utilities, and other consumers. Several methodologies are available to rate a module's peak power, but do any accurately predict energy output for flat-plate modules? This paper analyzes the energy performance of PV modules using six different energy calculation techniques and compares the results to the measured amount of energy produced. The results indicate which methods are the most effective for predicting energy output in Golden, Colorado, under prevailing meteorological conditions.
\end{abstract}

\section{INTRODUCTION}

The rating of photovoltaic (PV) modules can be classified in two ways: as a power rating or as an energy rating. A power rating is an instantaneous measurement with respect to a fixed set of reference conditions or a value that is based on a statistical analysis (e.g., regression). An energy rating is based on the amount of energy a module produces over a certain amount of time under specific conditions. Both of these rating methods have good applications. A power rating is an excellent way to compare modules under specific reference conditions. An energy rating gives a good comparison of module performance under actual operating conditions. Currently, there is no industry standard methodology to evaluate PV modules for energy production. This issue must be discussed and resolved for the benefit of system planners, utilities, and consumers. This paper compares different methods that are used to predict the energy output of PV modules and presents a comparison of results based on measurements obtained on various PV modules in Golden, Colorado.

There are basically two methods of rating the amount of peak power that modules produce. One is by calculating the instantaneous peak power from $\mathrm{H} V$ curves at specific conditions, such as Standard Reporting Conditions (SRC). The second method to rate power is to use regression analysis on long-term data of module power generation. These data can be used to form models of how the module operates at different meteorological and irradiance values. Rated power is then computed at a specific reference condition. PVUSA Test Conditions (PTC) and Nominal Terrestrial Environment (NTE) are examples of methods employing regression analysis. The reference criteria for these three methods are listed in Table 1.
Table 1. Reference criteria of module power rating test methods [1-4]

\begin{tabular}{|c|c|c|c|c|}
\hline Method & $\begin{array}{l}\text { Tradiance } \\
(\mathrm{W} / \mathrm{m})\end{array}$ & Temperatire & spectrom & Wind Speed \\
\hline SRC & 1000 & 25 (module) & AM1.5 & 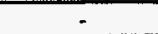 \\
\hline PTC & 1000 & 20 (ambient) & - & 1 \\
\hline NTE & 800 & 20 (ambient) & - & $\overline{1}$ \\
\hline
\end{tabular}

Once the amount of power a module produces at certain reference conditions is known, an energy rating can be determined. This is done by multiplying the instantaneous power by a selected period of time. For this paper, the time period is determined by the amount of peak sun-hours. One peak sun-hour is defined as the equivalent number of hours when the irradiance equals $1000 \mathrm{~W} / \mathrm{m}^{2}$ (i.e. 5 hours of irradiance at $200 \mathrm{~W} / \mathrm{m}^{2}$ equals 1 peak sun-hour). Multiplying the rated power $(W)$ by the number of peak sun-hours $(h)$ gives an approximate energy estimate in watt-hours (Wh). This method does not take into account changing temperature and spectral influences on the module, or the fact that the module may operate differently under different irradiance conditions.

Another method for determining a module energy rating is to use a "standard day" for the reference conditions and sum the energy generated over that standard day. This technique is used in the ENRA [4] and AM/PM [5] energy rating methods. This approach presents a standard method for comparing modules but may not give an accurate picture of the real operating conditions. Finally, the realistic reporting conditions (RRC) [6] method calculates the energy produced over a selected period of time usually monthly or annually, and takes into account actual or typical weather conditions. Typical weather conditions for a site can be found in typical meteorological year (TMY) data files, the Solar Radiation Data Manual for Flat-Plate and Concentrating Collectors [7] developed by the National Renewable Energy Laboratory (NREL), or the Solar and Meteorological surface observation network 1961-1990, available from the National Climatic Data Center [8].

This paper analyzes the energy performance of a set of modules using six different energy calculation techniques and compares the results to the measured amount of energy produced. The different energy rating methods that will be compared are described below.

1. Energy at SRC (ESRC): The module's peak power is determined at SRC and then the power is multiplied by the number of sun-hours during a specified time period to determine energy output. The module is rated at $25^{\circ} \mathrm{C}$; however, variations in temperature that the module may experience throughout the time period are not taken into account. This assumption will lead to significant discrepancies in energy output for modules that have relatively large 
temperature coefficients. Energy calculated by this method will typically be higher than the measured value.

2. Energy at PTC (EPTC): This method determines a power rating based on a regression analysis over a 30-day period, at PTC. Data are collected for at least 30 days, with a cumulative total of at least $10 \mathrm{kWh} / \mathrm{m}^{2}$ above $1000 \mathrm{~W} / \mathrm{m}^{2}$ of global plane-of-array irradiance. The rating is based on regression analysis of quality checked data using only irradiance of $500 \mathrm{~W} / \mathrm{m}^{2}$ or greater. The power is calculated using the following equation [4]:

$\mathbf{P}=\mathbf{A}_{1}{ }^{*} E+\mathbf{A}_{2}{ }^{*} E^{2}+\mathbf{A}_{3}{ }^{*} E^{*} T_{\text {amb }}+\mathbf{A}_{4}{ }^{*} E^{*} W S$

where, $\quad \mathbf{P}=$ output power, $\mathrm{Wdc}$

$E=$ irradiance, $W / m^{2}$

$T_{\text {amb }}=$ ambient air temperature, ${ }^{\circ} \mathrm{C}$

$W S=$ wind speed at $10 \mathrm{~m}$ above grade, $\mathrm{m} / \mathrm{s}$

$A_{n}=$ regression coefficients

The PTC-rated power is then multiplied by the number of sunhours during a specified time period to determine the energy rating. For this study, no wind speed restrictions were used.

3. Energy at NTE (ENTE): This method is similar to the EPTC except that the regression analysis is done at the Nominal Terrestrial Environment (NTE)[3]. The power rating is computed at $800 \mathrm{~W} / \mathrm{m}^{2}, 20^{\circ} \mathrm{C}$ ambient temperature, and wind speed of $1 \mathrm{~m} / \mathrm{s}$ using the PTC power model. Then the NTE-rated power is multiplied by the number of sun-hours during a specified time period to determine an energy rating.

4. ENRA (ENergy RAtings): This method also uses a regression analysis to determine the power output for each module using the following three parameter response function [5]

$P=A_{1} * E+A_{2} * E^{2}+A_{3} * E * \ln (E)$

where, $\quad P=$ output power, $W d c$

$E=$ irradiance, $W / \mathrm{m}^{2}$

$A_{n}=$ regression coefficients

Only data above $500 \mathrm{~W} / \mathrm{m}^{2}$ are used in computing the regression coefficients. The response function is then integrated over a reference day. The reference day is defined by the following function:

$$
\begin{aligned}
E(t)=\sum_{n=0}^{4} B_{n} t^{n}\left[W / m^{2}\right] \\
\mathbf{B}_{0}=2.602676742 \mathrm{e} 3 \\
\mathbf{B}_{1}=-1.399250090 \mathrm{e} 3 \\
\mathbf{B}_{\mathbf{2}}=2.43511524 \mathrm{e} 2 \\
\mathbf{B}_{3}=-1.5395308 \mathrm{e} 1 \\
\mathbf{B}_{4}=3.19483 \mathrm{e}-1 \\
t=\text { time in hours (from } t=6 \text { to } t=18 \text { ) }
\end{aligned}
$$

This function has a maximum of irradiance of $900 \mathrm{~W} / \mathrm{m}^{2}$ at $12: 00$, and its integral has a value of $6.82 \mathrm{kWh} / \mathrm{m}^{2}$, or 6.82 sun-hours. This model does not take into account temperature or spectral changes over the reference time period.

5. AM/PM: A model of power is obtained using derived temperature and irradiance coefficients for each module. The power equation is defined below:

$$
\mathbf{P}=\mathbf{P}_{\mathrm{irr}}{ }^{*}\left(1+10^{-5 \star} \mathrm{T}_{\text {coef }}{ }^{*}\left(\mathrm{~T}_{\text {mod }}-25^{\circ} \mathrm{C}\right)\right)
$$

where, $\quad \mathbf{P}=$ output power, Wdc

$P_{\text {irr }}=$ calculated power based on irradiance

$T_{\text {coef }}=\max$. power temp. coefficient in $\mathrm{ppm} /{ }^{\circ} \mathrm{C}$ normalized at $25^{\circ} \mathrm{C}$

$\mathrm{T}_{\text {mod }}=$ module temperature ${ }^{\circ} \mathrm{C}$

Calculated power based on irradiance is derived from the following formula:

$P_{\mathrm{irr}}=m^{\star} I_{s c}+b=m * E_{t o t} /\left(1000 * I_{s r c}\right)+b$

where, $\left.\right|_{\mathrm{sc}}=$ short circuit current

$$
\begin{aligned}
& E_{\text {tot }}=\text { total irradiance, } W / \mathrm{m}^{2} \\
& I_{\text {src }}=I_{\text {sc }} \text { at } 25^{\circ} \mathrm{C} \text { and } 1000 \mathrm{~W} / \mathrm{m}^{2}
\end{aligned}
$$

This function assumes that $I_{s c}$ is linear with total irradiance and temperature. The module temperature is computed from the following equation [9]:

$\Delta T=T_{\text {mod }}-T_{\text {air }}=0.314^{*} E_{\text {tot }}(1-\eta) /\left(1+0.4^{*} V^{1 / 3}\right)(6)$

where, $\quad T_{\text {air }}=$ air temperature, ${ }^{\circ} \mathrm{F}$

$E_{\text {tot }}=$ total irradiance, $W / \mathrm{ft}^{2}$

$\eta=$ efficiency $=P_{\text {ind }} /\left(\right.$ Area $\left.{ }^{*} E_{\text {tor }}\right)$

$V=$ wind velocity, $\mathrm{ft} / \mathrm{sec}$

A better fit to the measured-versus-calculated module temperature was obtained when 0.15 was used instead of the 0.314 suggested by the reference. The energy over a standard day is then computed by multiplying the calculated power by the amount of time during a standard day. An "AM/PM" standard day is defined as a function of insolation, temperature, and air mass variations over a 24-hour period. For this experiment, only irradiance and temperature were defined. The equations below for the irradiance and temperature models were derived from a polynomial curve fit to the figures in the reference [5].

$$
\begin{aligned}
E(t)=\sum_{n=0}^{4} B_{n} t^{n}\left[W / m^{2}\right] \\
\mathbf{B}_{0}=2.965956 \mathrm{e} 3 \\
\mathbf{B}_{1}=-1.484969 \mathrm{e} 3 \\
\mathbf{B}_{2}=2.457535 \mathrm{e} 2 \\
\mathbf{B}_{3}=-1.532984 \mathrm{e} 1 \\
\mathbf{B}_{4}=3.195195 \mathrm{e}-1 \\
\mathbf{t}=\text { time in hours (from } \mathrm{t}=6 \text { to } \mathrm{t}=18 \text { ) }
\end{aligned}
$$

This function has an integral value of $5.35 \mathrm{kWh} / \mathrm{m}^{2}$, or 5.35 sun-hours.

$$
\begin{aligned}
\text { Air_Temp }(t) & =\sum_{n=0}^{6} \mathbf{B}_{n} t^{n}\left[W / m^{2}\right] \\
\mathbf{B}_{0} & =-1.276272 \mathrm{e} 1 \\
\mathbf{B}_{1} & =2.454010 \mathrm{e} 1 \\
\mathbf{B}_{2} & =-7.683963 \\
\mathbf{B}_{3} & =1.115173 \\
\mathbf{B}_{4} & =-8.009432 \mathrm{e}-2 \\
\mathbf{B}_{5} & =2.801611 \mathrm{e}-3 \\
\mathbf{B}_{6} & =-3.848843 \mathrm{e}-5 \\
t & =\text { time in hours (from } t=6 \text { to } t=18 \text { ) }
\end{aligned}
$$

6. RRC: A model for module power is obtained though laboratory characterization. The same power model that was 
used for the AM/PM method was used for this methodology. The energy is then summed over a specific time period using realistic meteorological conditions. For this paper, hourly averages of actual measured meteorological data were used to calculate the amount of energy that each module produced. This should lead to accurate predictions of energy, if the power models for each module are valid.

\section{EXPERIMENTAL}

A set of modules at NREL has been deployed outdoors and loaded at the peak power point. The modules' voltage and current are measured every $5 \mathrm{~s}$ and averaged hourly. This provides the measured energy produced by each module in watt-hour(Wh). A set of seven modules has been selected to represent major types of terrestrial flat-plate PV modules. This set includes single-crystalline silicon (mono-Si); multicrystalline silicon (multi-Si); single-, dual-, and triple-junction amorphous silicon (a-Si, a-Si/a-Si); and a-Si/a-Si/a-Si); copper indium diselenide ( $\mathrm{CIS}$ ); and cadmium telluride ( $\mathrm{CdTe}$ ) modules. Each module's I-V curve is also taken every half hour and stored. These data are used, along with meteorological and radiometric data, to compute regression coefficients for various module performance evaluation models. The meteorological and radiometric data at the site are collected at the Reference Meteorological and Irradiance Station (RMIS). These data include ambient temperature, plane-ofarray (POA) irradiance, direct normal irradiance, and wind speed. These data are used to compute power equations for each module using regression analysis over a period of 30 days. The 30-day period that was used for this study was the month of September, 1994.

Module temperature and irradiance coefficients for the AM/PM and RRC energy ratings methods were developed using a Spire 240 solar simulator. Irradiance measurements were taken between 0.1 and 1.2 suns, with the temperature held to $25 \pm 0.5^{\circ} \mathrm{C}$. Temperature measurements were taken between $10^{\circ} \mathrm{C}$ and $50^{\circ} \mathrm{C}$, with the irradiance held at 1000 $\mathrm{W} / \mathrm{m}^{2}$.

The modules' energy output is compared with the amount predicted by using six different energy rating methods over a clear day, a cloudy day, and a month. The clear day was September 8,1994 . This day had a total sun-hours of 7.65 sun-hours and an average daily temperature of $22^{\circ} \mathrm{C}$. The cloudy day was September 30, 1994. This day had a total of 2.21 sun-hours and an average daily temperature of $15^{\circ} \mathrm{C}$. The month used was September, 1994, which had a total of 171 sun-hours and an average temperature of $18^{\circ} \mathrm{C}$.

Table 2 lists the modules used in this study along with their manufacturers' rated power. Some modules do not contain manufacturer ratings because they are research modules. The table also includes the modules' rated power measured at SRC, and calculated power ratings at PTC and NTE. The table also contains the nominal operating cell temperature (NOCT) for each module for the month of September. The regression analysis for both the PTC and NTE consisted of the 30 days of the month of September. Only data with irradiance above $500 \mathrm{~W} / \mathrm{m}^{2}$ were used. All power ratings are normalized to $1000 \mathrm{~W} / \mathrm{m}^{2}$.
Table 2. Power rating of modules and module NOCT

\begin{tabular}{|l|c|c|c|c|c|}
\hline $\begin{array}{c}\text { Module } \\
\text { Type }\end{array}$ & Manf & SRC & NIE & PTC & NoCT \\
\hline a-Si & 5 & 3.27 & 3.1 & 3.1 & (W) \\
\hline a-Si/a-Si & 22 & 19.6 & 18.0 & 18.9 & 33.2 \\
\hline a-Si/a-Si/a-Si & - & 25.1 & 23.6 & 24.7 & 31.7 \\
\hline mono-Si & 75 & 67.2 & 60.7 & 60.8 & 30.9 \\
\hline multi-Si & 60 & 53.9 & 49.0 & 49.2 & 29.6 \\
\hline CIS & - & 31.4 & 24.6 & 25.8 & 33.1 \\
\hline CdTe & - & 53.6 & 41.4 & 42.9 & 36.9 \\
\hline
\end{tabular}

\section{RESULTS AND DISCUSSION}

Tables 3 and 4 show a comparison of measured energy output (Wh) versus different rating methods for September 8 , 1994. This is considered a good solar day in Golden, Colorado.

Table 3. Measured energy (Wh) versus percent difference (\%) for a dear day

\begin{tabular}{|l|c|c|c|c|}
\hline NoduleT TYPe & Meas & ESRC & ENTE & EPTC \\
\hline a-Si & 23.6 & 5.6 & 5.2 & 0.4 \\
\hline a-Si/a-Si & 141.1 & 5.8 & 1.7 & 2.4 \\
\hline a-Si/a-Si/a-Si & 186.3 & 2.9 & 1.1 & 1.4 \\
\hline mono-Si & 454.0 & 11.8 & 6.2 & 2.4 \\
\hline multi-Si & 371.5 & 9.9 & 5.0 & 1.3 \\
\hline ClS & 187.8 & 21.8 & 4.2 & 4.9 \\
\hline CdTe & 329.3 & 19.7 & 0.2 & -0.3 \\
\hline
\end{tabular}

Table 3 shows that, for a clear day, the ESRC method overpredicts energy outputfor all module types. The ESRC values for a-Si are much closer to the measured values because these modules are not as temperature sensitive as crystalline silicon or other thin-films. The ENTE and EPTC methods predict module energy output within $6 \%$ for most technologies on clear days. The regression analysis works well because the models for the technologies are stable, and predict well, especially on clear days.

Table 4. Measured energy (Wh) versus percent difference (\%) for a clear day

\begin{tabular}{|l|c|c|c|c|}
\hline Module Type & Meas & ENRA & AM/PM & RRC \\
\hline a-Si & 23.6 & -11.3 & -30.4 & 6.3 \\
\hline a-Si/a-Si & 141.1 & -11.9 & -40.0 & 3.2 \\
\hline a-Si/a-Si/a-Si & 186.3 & -12.8 & -46.6 & 0.7 \\
\hline mono-Si & 454.0 & 7.4 & -33.0 & 0.9 \\
\hline multi-Si & 371.5 & -1.0 & -35.2 & 0.1 \\
\hline CIS & 187.8 & -7.3 & -24.1 & 9.6 \\
\hline CdTe & 329.3 & -6.8 & -15.1 & 14.4 \\
\hline
\end{tabular}

Table 4 shows that, for a clear day, the ENRA and AM/PM methods under-predict the energy produced for all modules except one. This is because the ENRA and AM/PM method base their energy output on a standard day where the total irradiance was less than that of the clear day. The RRC method was extremely close to the measured value except for the a-Si, CIS and CdTe modules. This is because the models for these technologies may not be accurate (i.e., more scatter or bias in data).

Tables 5 and 6 show a comparison of measured energy output (Wh) versus different rating methods for September 8 , 1994. This is considered a cloudy day for the month of September in Golden, Colorado. 
Table 5. Measured energy (Wh) versus percent difference (\%) for a cloudy day

\begin{tabular}{|l|c|c|c|c|}
\hline Module Type & Meas: & ESRC & ENTE & EPTC \\
\hline a-Si & 7.1 & 1.4 & 1.4 & -4.4 \\
\hline a-Si/a-Si & 43.8 & -1.4 & -5.8 & -5.0 \\
\hline a-Si/a-Si/a-Si & 56.5 & -2.2 & -4.0 & -3.9 \\
\hline mono-Si & 141.6 & 4.6 & -1.4 & -5.4 \\
\hline multi-Si & 115.2 & 3.3 & -2.0 & -6.0 \\
\hline CIS & 56.7 & 18.2 & -0.2 & 0.5 \\
\hline CdTe & 101.7 & 14.1 & -6.7 & -7.3 \\
\hline
\end{tabular}

Table 5 shows that, for a cloudy day, the ESRC method predicts energy within 3\% for a-Si and within $5 \%$ for monoand multi-Si modules. This is due to the lower operating temperatures under cloudy sky conditions. For CIS and CdTe modules, the SRC method overestimates energy output up to $18 \%$. The ENTE and EPTC methods predicts module energy output within $8 \%$ for most technologies on cloudy days.

Table 6. Measured energy (Wh) versus percent difference (\%)

\begin{tabular}{|l|c|l|l|l|}
\hline Module Type & Meas. & \multicolumn{1}{|c|}{ ENRA } & AM/PM & RRC \\
\hline a-Si & 7.1 & 66.5 & 60.8 & 15.5 \\
\hline a-Si/a-Si & 43.8 & 65.3 & 56.5 & -12.9 \\
\hline a-Si/a-Si/a-Si & 56.6 & 65.7 & 55.5 & -21.7 \\
\hline mono-Si & 141.6 & 71.1 & 58.5 & -0.3 \\
\hline multi-Si & 115.2 & 68.7 & 58.1 & -3.6 \\
\hline CIS & 56.7 & 67.6 & 62.5 & -0.2 \\
\hline CdTe & 101.7 & 67.0 & 64.4 & 18.5 \\
\hline
\end{tabular}

Table 6 shows that, for a cloudy day, the ENRA and AM/PM methods over-predict the energy produced for all modules by at least $55 \%$. This is because the ENRA and AM/PM method base their energy output on a standard day where the total irradiance was more than that of the cloudy day. The RRC method had a lot of variation in predicting energy output. This method's estimation is very close for mono-si and CIS. This is because the models for these technologies are accurate at low irradiance levels.

Tables 7 and 8 show a comparison of measured energy output ( $\mathrm{kWh}$ ) versus different rating methods for September, 1994.

Table 7. Measured energy ( $k W h$ ) versus percent difference (\%) for the month of September 1994

\begin{tabular}{|l|c|c|c|c|}
\hline Module Type & Meas & ESRC & ENTE & EPTC \\
\hline a-Si & 0.53 & 4.7 & 4.1 & -0.6 \\
\hline a-Si/a-Si & 3.15 & 5.7 & 1.6 & 2.4 \\
\hline a-Si/a-Si/a-Si & 4.13 & 3.5 & 1.8 & 2.1 \\
\hline mono-Si & 10.25 & 10.7 & 5.0 & 1.2 \\
\hline multi-Si & 8.41 & 8.6 & 3.7 & -0.1 \\
\hline CIS & 4.22 & 21.2 & 3.5 & 4.2 \\
\hline CdTe & 7.34 & 19.7 & 0.3 & -0.2 \\
\hline
\end{tabular}

Table 7 shows that, for the month of September, the ESRC method predicts energy within $6 \%$ for a-Si and within $11 \%$ for mono- and multi-Si modules. For CIS and CdTe modules, the ESRC method overestimates energy output by $22 \%$. The ENTE and EPTC methods can predict module energy output within $5 \%$ for all technologies for the month of September
Table 8 . Measured energy ( $k W h$ ) versus percent difference (\%) for the month of September 1994

\begin{tabular}{|l|c|c|c|c|}
\hline Module Type & Meas & ENRA & AM/PM & RRC \\
\hline a-Si & 0.53 & 16.5 & 0.4 & 7.5 \\
\hline a-Si/a-Si & 3.15 & 16.7 & -4.2 & 2.1 \\
\hline a-Si/a-Si/a-Si & 4.13 & 16.7 & -8.4 & -1.2 \\
\hline mono-Si & 10.25 & 30.3 & -0.1 & 3.4 \\
\hline multi-Si & 8.41 & 23.8 & -2.0 & 1.7 \\
\hline CIS & 4.22 & 19.7 & 7.0 & 10.5 \\
\hline CdTe & 7.34 & 20.6 & 14.4 & 17.7 \\
\hline
\end{tabular}

Table 8 shows that, for the month of September 1994, the ENRA method overestimates the energy produced for all module types. This is because the standard day that this method uses is considered a clear day, and this method applies no corrections for temperature. The AM/PM method come considerably closer to predicting a monthly energy output because its standard day is a well-defined average day, and it incorporates temperature effects on modules. The RRC method predicts energy very well for technologies that have a well-defined model for performance, but did not predict as well for technologies where the models for their performance are not well known.

\section{CONCLUSIONS}

The ESRC methodology does not accurately predict module energy output for modules that are temperature-sensitive when the modules operate at elevated temperatures. This is because there are no temperature corrections in the power or energy ratings. The ESRC method is a good predictor of energy only when the modules operating conditions are close to the standard reporting conditions.

Methodologies that use regression analyses like EPTC and ENTE can accurately predict energy output if the regression and prediction are computed for the same time periods. The equations that are developed with regression analyses may not be valid if the module's response changes over conditions that were not used in the regression. An example would be using models developed from summer data, which might not accurately predict winter energy output. Scatter in the data used to derive the models will lead to less-accurate predictions.

Standard day techniques, such as the ENRA and AM/PM, work well for long-term averages if the standard day is representative of an average day in a particular area. These methods do not do well in predicting energy for days or periods when the conditions are not close to the standard day. The energy totals for these methods would be closer to the actual values if they were corrected back to the actual amount of irradiance on a daily basis.

The RRC method works well at predicting energy for modules if the power models for the technology are accurate and stable. This paper showed that the RRC method works well when using actual meteorological and irradiance data, but these results will vary if one were to use typical monthly or yearly data.

\section{FUTURE WORK}

The Photovoltaic Module and Systems Performance and Engineering Project at NREL will continue to study the issue of module energy ratings. Work needs to be conducted on 
developing better models that predict how modules perform under a variety of meteorological conditions. This will lead to more accurate energy predictions. Also, a decision must be made regarding calculating energy based on standard or typical conditions or actual conditions.

\section{ACKNOWLEDGEMENTS}

The authors thank Richard DeBlasio for his support of energy ratings work in this project. The authors also thank Jerry Anderson, Yehoshua Caiyam, Steve Rummel, and Larry Ottoson for their help with module characterization and temperature coefficient development, and Troy Strand for stimulating technical discussions. This work was supported by the U.S. Department of Energy under contract No. DE-AC36$83 \mathrm{CH} 10093$.

\section{REFERENCES}

[1] "Standard Tables for Terrestrial Solar Spectral Irradiance at Air Mass 1.5 for a $37^{\circ}$ Tilted Surface," ASTM E 892.

[2] S. Nann and K. Emery, "A Numerical Analysis of PV-Rating Methods," 22nd IEEE PVSC, OCt. 1991.

[3] "Standard Test Methods Electrical Performance of Nonconcentrator Terrestrial Photovoltaic Modules and Arrays Using Reference Cells," ASTM E 1036.

[4] PVUSA Technical Specifications, 19271-EMT-3, Aug. 1991.

[5] E. Gianoli-Rossi and K. Krebs, "Energy Rating of PV Modules by Outdoor Response Analysis," 8th E.C. PV Solar Energy Conference. Florence, Italy, 1988.

[6] C.F. Gay, J.E. Rumberg, and J.H. Wilson, "AM/PM - All-Day Module Performance Measurements," 16th IEEE PVSC, San

Diego, CA. 1982.

[7] K. Bücher, "Do We Need Site-Dependent and ClimateDependent Module Rating?," 23rd IEEE PVSC, Louisville, KY, 1993.

[8] National Climatic Data Center, Solar and Meteorological Surface Observation Network 1961-1990, Ver. 1.0, September 1993.

[9] E.M. Sparrow and K.K. Tien, "Forced Convection Heat Transfer at an Inclined and Yawed Square Plate-Application to Solar Collectors،" J. Heat Transfer, Vol. 99, pp. 507-512, 1977. 